\title{
Actividade Policial como Ciência ${ }^{1}$
}

Germano Marques da Silva

Professor CaTEDRÁtico do ISCPSI $\mathrm{E}$

Universidade Católica Portuguesa - Lisboa - Portugal

\section{RESUMO}

A presente palestra constitui reflexão sobre a possibilidade de fala acerca de uma ciência policial. A experiência deste autor na Escola Superior de Polícia Portuguesa, na qual foi responsável pela criação do primeiro curriculum, demonstra o princípio de que a atuação policial deve ser procedida em consonância com o direito, a cultura do povo e os princípios éticos. É nesse sentido que se afirma a importância do ensino do Direito, da Filosofia Política e da Ética Policial, bem como a necessidade de que o ensino delas esteja contextualizado a práxis policial e social. Por essa necessidade de conhecimentos em múltiplas áreas, o autor afirma ainda ser cedo para se pensar em autonomia das ciências policiais.

Palavras-Chave: A experiência do ensino na Escola Superior de Polícia/ISCPSI portuguesa. Actividade Policial como Ciência?

\section{INTRODUÇÃO}

Tinha ficado com a ideia que deveria falar-vos de Polícia e Direitos Fundamentais, mas fui surpreendido com o programa e tema desta oficina "As ciências policiais no Brasil/Actividade Policial como Ciência". Tenho muitas dúvidas se a actividade policial é já uma ciência, mas não tenho dúvida alguma de que o Direito é componente essencial da actividade policial, que os Direitos e Liberdades Fundamentais são pressuposto e limite da actuação policial e que a metodologia do ensino e aprendizagem do Direito pelos polícias tem características próprias, distintas das demais profissões jurídicas. $\mathrm{O}$

1 Palestra apresentada no II Congresso Brasileiro das Carreiras Jurídicas de Estado durante as atividades da oficina Actividade Policial como Ciência. 
Direito prossegue a Justiça e a Segurança colectivas; a polícia tem de cuidar da segurança de cada cidadão não podendo sacrificar à segurança colectiva os direitos e liberdades individuais. É equilíbrio difícil, sempre problemático, a exigir em cada intervenção policial muita prudência e diligência para cuidar das consequências e evitar os excessos.

É na busca deste equilíbrio, da conciliação prática entre os valores que o Direito prossegue e a sua realização em cada intervenção policial que se desenha uma nova metodologia, a metodologia da intervenção policial, que não é só técnica ou arte, é actuação com grande exigência ética e que alguns autores modernos pretendem constituir o objecto específico de uma nova ciência: a Ciência Policial.

Entendo as especificidades inerentes à formação policial. Fui o responsável há mais de 25 anos pela elaboração do primeiro curriculum da então Escola Superior de Polícia portuguesa, hoje denominada Instituto Superior de Ciências Policiais e Segurança Interna que forma os quadros superiores da Polícia de Segurança Pública em Portugal.

Recordo a minha principal preocupação de então. Para além das disciplinas técnicas e jurídicas já experimentadas na formação dos polícias, propus que fosse destinada uma carga horária considerável ao ensino dos Direitos e Liberdades Fundamentais, à Filosofia Política, à Cultura Portuguesa e à Ética Policial. Escuso de dizer que nos primeiros tempos fui quase escarnecido por querer formar polícias doutores, em vez de me preocupar essencialmente com a eficácia da sua intervenção. Acabávamos de sair da Revolução de Abril, mas eram muitas ainda as vozes que vinham do passado a reclamar sobretudo a eficácia da intervenção policial. Que era mais importante saber manejar devidamente o casse-tête do que conhecer os direitos de cada cidadão, a cultura do povo e os princípios e limitaçôes éticas, diziam alguns Velhos do Restelo! Aquelas propostas foram adoptadas e hoje são aquisição indiscutível nos curricula das Escolas Superiores de Polícia portuguesas.

\section{A Experiência do Ensino na Escola Superior de Polícia/ISCPSI Portuguesa}

Nestes 25 anos de vida do Instituto Superior de Ciências Policiais e Segurança Interna português, o curriculum tem sido alterado para acompanhar as novas competências atribuídas à PSP, embora o núcleo essencial das disciplinas leccionadas se mantenha. 
Permitam-me uma referência aparentemente anedótica mas real. A par da inclusão no plano de estudos das quatro disciplinas já referidas, considero hoje que o acto mais significativo em termos de projecção no advir e sucesso da Escola foi a admissão de mulheres nos seus Cursos de Oficiais de Polícia. Já então havia mulheres polícias, mas não mulheres Oficiais de Polícia. A admissão para o primeiro Curso de uma mulher foi uma batalha dura. Muitos defendiam que na Polícia deveria haver um quadro administrativo e um quadro operacional e que só para aquele deveriam ser admitidas mulheres. Os argumentos eram muitos, mas fracos; quase sempre assentes nas exigências de preparação física dos polícias operacionais e na condição física das mulheres. No presente, mesmo os mais conservadores, aplaudem a integração plena. Mérito e exemplo das Senhoras Oficiais formadas pelo ISCPSI.

Com a atribuiçãa de competência à PSP para a investigação criminal, competência de que carecia à data da fundação da Escola, foi necessário alterar o plano de estudo para introduzir disciplinas ligadas à investigação e aprofundar a formação nas áreas do Direito e do Processo Penal e da Política Criminal. A experiência da Escola vem mostrando, e são disso testemunho bastante as dissertações de final de Curso, que os métodos do ensino destas disciplinas, especialmente no processo penal e investigação criminal, não podem ser iguais aos seguidos nas Faculdades. A dogmática, que é a base, tem de ter sempre presente a jurisprudência dominante e há que dar especial enfoque aos modos e limites da intervenção policial, prestando especial cuidado à forma dos actos para que não haja excessos na actuação policial e não se viciem as provas por incorrecção no uso dos meios para a sua obtenção. Esta perspectiva, de a par do conhecimento da norma estudar os meios admissíveis para a intervenção policial nos casos da vida, é uma das características que distinguem o ensino daquelas disciplinas.

O ensino dos Direitos e Liberdades Fundamentais caminha a par da Filosofia Política e da Ética Policial. Verdadeiramente, também agora para além das normas e dos princípios filosóficos que as informam, importa despertar o espírito dos estudantes e formá-los no ideal democrático, nas virtudes e no culto da liberdade que o integram. É um diálogo permanente que não se limita à sala de aula mas passa necessariamente pelo acompanhamento por parte dos docentes e quadros policiais na formação do Corpo de Alunos. É preciso educar os jovens estudantes para as exigências de uma polícia democrática e para educar não basta dar a conhecer, é preciso também e sobretudo exigir a prática das virtudes que se aprendem praticando. Liberdade total, mas 
tolerância zero, porque Polícia é Cultura, é civilização, escrevia Camões nos Lusíadas, e para conhecer o grau de civilização de um povo deve começar-se por «ver a polícia desse povo».

O ensino policial tem de ser um ensino dinâmico, muito atento à própria dinâmica social e política da sociedade porque a Polícia está na sociedade, no seu seio, faz parte dela e deve ser motor na busca do bem comum e espelho da comunidade que serve. A polícia não está ao serviço dos Governos; existe para servir o Estado/Comunidade, os cidadãos. Por isso que a autonomia na acção seja essencial, a justificar o aprofundamento na Escola das disciplinas de Direito Constitucional (fins e funções do Estado) e Ética Policial (deontologia profissional) que exige liberdade com responsabilidade.

\section{Actividade Policial como Ciência?}

O tempo escoa-se e já lá vão os meus quinze minutos. Não tratei ainda com profundidade e rigor científico do tema anunciado para esta oficina. Nem vou tratar, desculpem. É que entendo que é cedo ainda para se falar em autonomia das ciências policiais. $\mathrm{O}$ oficial de polícia tem de ser quase enciclopédico, tem de ser culto, tantas e tão diversas são as solicitações a que tem de acudir. Tem de estudar Direito, Sociologia, Psicologia, Matemática e Física; tem de dominar línguas, técnicas policiais de prevenção e repressão, tem de conhecer as ciências auxiliares da investigação criminal e tanto mais. Não será certamente a multiplicidade de matérias que constitui o objecto específico de uma nova ciência. Creio é que as várias ciências que compõem o leque de formação necessária aos Oficiais de Polícia, têm de ser tratadas na perspectiva da sua aplicação prática. A teoria importa, mas apenas como preparação para a intervenção policial, para a prática. É neste caminho, do método de ensino e aprendizagem, que me parece que as escolas de formação dos oficiais de polícia devem caminhar. Uma nova ou novas ciências? Talvez, tendo em conta a exigência de métodos próprios. Não é importante.

\section{Conclusão}

Vou fechar, concluindo a intervenção, mas sem conclusões sobre o objecto do painel, desta oficina. Faço-o recordando ainda as polémicas que travámos em Portugal vai para 30 anos sobre o perfil ideal do polícia e sobre 
as exigências da sua formação académica em vista à profissionalização. Sobre o perfil ainda andamos à procura... Entendemos então que a formação ideal deveria ser feita de raiz, atenta a complexidade e diversidade das matérias que o Oficial de Polícia tem de dominar, mas não só e nem sobretudo por isso: porque é na aprendizagem constante dos valores da liberdade e do culto da liberdade dos outros que se faz um democrata, que é exigente e tolerante, corajoso e humilde, prudente e justo, como deve ser o polícia do nosso tempo. A Escola e o ambiente imposto pelo espírito de corpo e de serviço faz-se porventura melhor numa Escola especialmente vocacionada. Assim acreditámos e assim o creio ainda.

Muito obrigado. Saudações deste português que ama o Brasil.

Germano Margues da Silva Professor Catedrático do ISCPSI e Universidade Católica Portuguesa - Lisboa - Portugal

\begin{abstract}
This lecture is a reflection about the possibility to think about a police science. The experience of this writer on the College of Portuguese Police, in which was responsible for the creation of the first curriculum, show the principle that the police works has to be proceeded sync with the law, the culture of the people and the ethical principles. Is in this sense that we say about the importance of teaching about laws, political philosophy and police ethics, and the necessity of his teaching will be in context with the police and social praxis. Because this necessity of knowledge in multiple areas, the writer says to be too early to think about in autonomy of police science.
\end{abstract}

KEYWORDS: The experience of teaching in the High School of Police / ISCPSI Portuguese. Police activity as Science?

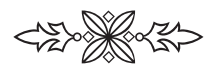

